Meta

Journal des traducteurs

Translators' Journal

\title{
Le(s) processus de la traduction. Avant-propos
}

\section{Frank G. Königs}

Volume 41, numéro 1, mars 1996

Le(s) processus de traduction / Translation Process(es)

URI : https://id.erudit.org/iderudit/003340ar

DOI : https://doi.org/10.7202/003340ar

Aller au sommaire du numéro

Éditeur(s)

Les Presses de l'Université de Montréal

ISSN

0026-0452 (imprimé)

1492-1421 (numérique)

Découvrir la revue

Citer ce document

Königs, F. G. (1996). Le(s) processus de la traduction. Avant-propos. Meta, 41(1),

6-6. https://doi.org/10.7202/003340ar d'utilisation que vous pouvez consulter en ligne.

https://apropos.erudit.org/fr/usagers/politique-dutilisation/ 


\section{LE(S) PROCESSUS DE LA TRADUCTION. AVANT-PROPOS}

FRANK G. KÖNIGS

Institut Herder, Universitê de Leipzig, Leipzig, Allemagne

La traductologie est en train de changer de profil depuis quelques années. L'une des manifestations de ce changement réside dans la remise en question de plus en plus marquée au niveau international quant à la traduction comme processus. Ainsi, à côté de cette branche établie de la traductologie, dont l'objet était traditionnellement le produit fini, on trouve à présent une nouvelle branche qui a pour champ d'investigation bien défini le traitement mental des problèmes posés par la traduction. Cette branche est, comparée aux autres domaines de la traductologie, un champ d'investigation encore très récent dont les résultats ne doivent pas être survalorisés, certes, mais qui justifient la supposition d'après laquelle quelques hypothèses traditionnelles à propos de la traduction doivent, pour le moins, faire l'objet d'une révision.

Ce numéro spécial comprend des articles venant de pays différents (Allemagne, Angleterre, Canada, Chili, Danemark, Finlande) et dans lesquels les auteurs discutent du processus de la traduction en s'appuyant sur des méthodes de recherche différentes.

En fait, l'ensemble des contributions est à interpréter, d'une part, comme une invitation à continuer de s'intéresser à ce nouvel aspect de la traduction et, d'autre part, comme une information sur quelques résultats qui ont pu, jusqu'à présent, être obtenus en la matière - ni plus ni moins.

Nous tenons à exprimer tous nos remerciements à Beate Helbig pour la préparation technique des manuscrits. 